\title{
Towards a consensus-based biokinetic model for green microalgae - The ASM-A
}

Wágner, Dorottya Sarolta; Valverde Pérez, Borja; Sæbø, Mariann; Bregua de la Sotilla, Marta; van Wagenen, Jonathan Myerson; Smets, Barth F.; Plósz, Benedek G.

Published in:

Water Research

Link to article, DOI:

10.1016/j.watres.2016.07.026

Publication date:

2016

Document Version

Peer reviewed version

Link back to DTU Orbit

Citation (APA):

Wágner, D. S., Valverde Pérez, B., Sæbø, M., Bregua de la Sotilla, M., van Wagenen, J. M., Smets, B. F., \& Plósz, B. G. (2016). Towards a consensus-based biokinetic model for green microalgae - The ASM-A. Water Research, 103, 485-499. https://doi.org/10.1016/j.watres.2016.07.026

\section{General rights}

Copyright and moral rights for the publications made accessible in the public portal are retained by the authors and/or other copyright owners and it is a condition of accessing publications that users recognise and abide by the legal requirements associated with these rights.

- Users may download and print one copy of any publication from the public portal for the purpose of private study or research.

- You may not further distribute the material or use it for any profit-making activity or commercial gain

- You may freely distribute the URL identifying the publication in the public portal 


\section{Towards a consensus-based biokinetic model for green}

2 microalgae - the ASM-A

3 Dorottya S. Wágner ${ }^{1, *}$, Borja Valverde-Pérez ${ }^{1, *}$, Mariann Sæbø, Marta Bregua de la Sotilla, Jonathan Van Wagenen,

4 Barth F. Smets, Benedek Gy. Plósz*

5 Department of Environmental Engineering, Technical University of Denmark, Miljøvej, Building 113, 2800 Kgs.

6 Lyngby, Denmark

$7 \quad 1$ Joint first authors

8 *Corresponding authors: dosaw@env.dtu.dk; bvape@env.dtu.dk; beep@env.dtu.dk

10 ABSTRACT

11 Cultivation of microalgae in open ponds and closed photobioreactors (PBRs) using wastewater

12 resources offers an opportunity for biochemical nutrient recovery. Effective reactor system design

13 and process control of PBRs requires process models. Several models with different complexities

14 have been developed to predict microalgal growth. However, none of these models can effectively

15 describe all the relevant processes when microalgal growth is coupled with nutrient removal and

16 recovery from wastewaters. Here, we present a mathematical model developed to simulate green

17 microalgal growth (ASM-A) using the systematic approach of the activated sludge modelling

18 (ASM) framework. The process model - identified based on a literature review and using new

19 experimental data - accounts for factors influencing photoautotrophic and heterotrophic

20 microalgal growth, nutrient uptake and storage (i.e. Droop model) and decay of microalgae. Model

21 parameters were estimated using laboratory-scale batch and sequenced batch experiments using 
22 the novel Latin Hypercube Sampling based Simplex (LHSS) method. The model was evaluated

23 using independent data obtained in a 24-L PBR operated in sequenced batch mode. Identifiability

24 of the model was assessed. The model can effectively describe microalgal biomass growth,

25 ammonia and phosphate concentrations as well as the phosphorus storage using a set of average

26 parameter values estimated with the experimental data. A statistical analysis of simulation and

27 measured data suggest that culture history and substrate availability can introduce significant

28 variability on parameter values for predicting the reaction rates for bulk nitrate and the

29 intracellularly stored nitrogen state-variables, thereby requiring scenario specific model

30 calibration. ASM-A was identified using standard cultivation medium, and it can provide a

31 platform for extensions accounting for factors influencing algal growth and nutrient storage using

32 wastewater resources.

33

34 KEYWORDS

35 Process modelling; Green microalgal growth; Nutrient storage; Parameter identifiability;

36 Uncertainty and global sensitivity analysis. 


\section{INTRODUCTION}

38 Cultivation of green microalgae has been proposed as a suitable technology for wastewater

39 remediation due to their capacity to remove nitrogen and phosphorus (Markou et al., 2014).

40 Consequently, several studies have explored the integration of microalgal cultivation in existing

41 wastewater treatment plants (WWTPs), focusing on high pollutant removal from high strength

42 streams, e.g. effluent from anaerobic digester, or as a tertiary treatment step (Wang et al., 2010;

43 Van Den Hende et al., 2014; Boelee et al., 2011). However, due to an increasing global population,

44 climate change and industrialization, in the near future, we will be facing new global challenges,

45 such as severe water scarcity (Bixio et al., 2006; Verstraete et al., 2009) or the depletion of non-

46 renewable phosphorus resources (Verstraete et al., 2009; Desmidt et al., 2015). Consequently,

47 sewage, referred to as used water, should be considered as a source of energy, nutrients and fresh

48 water rather than a waste (Verstraete and Vlaeminck, 2011). Cultivation of microalgae offers the

49 potential to recover water, nitrogen and phosphorus from used water providing an opportunity for

50 residual nutrient recycling (Shilton et al., 2012; Cai et al., 2013; Samorí et al., 2013; Mehta et al.,

51 2015). Moreover, it has been demonstrated that microalgal biomass can be used as a slow-leaching

52 fertilizer (Mulbry et al., 2005). Hence, as an alternative to the conventional algal cultivation for

53 nutrient removal from used water, Valverde-Pérez et al. (2015) propose an enhanced biological

54 phosphorus recovery and removal (EBP2R) process, able to provide optimal cultivation media for

55 green microalgal growth. The EBP2R combined with an algal PBR, referred to as TRENS system

56 (Fang et al., 2016), is then able to produce an algal suspension where nutrients are stored in the

57 algal biomass, which can be used for fertigation. Additionally, algal biomass can be used for biogas

58 or biodiesel production (Mata et al., 2010; Wijffels et al., 2010; Perez-Garcia et al., 2011). Unlike

59 crop-based biofuels, microalgal biomass does not compete with agricultural land used for food 
60 production, qualifying it as a third generation biofuel (Clarens et al., 2010). Nevertheless, typical

61 cultivation of microalgae can have a high water and energy demand and a high greenhouse-gas

62 footprint associated with the production of fertilizer used for cultivation (Clarens et al., 2010;

63 Guieysse et al., 2013; Markou et al, 2014). Hence, large-scale microalgal cultivation for biofuel

64 production appears neither energetically nor economically favourable, unless it is coupled with

65 used water resource recovery and treatment (Lundquist et al., 2010; Pittman et al, 2011; Chen et

66 al., 2015).

67 The existing process modelling approaches (Table S1, SI) range in complexity, comprising models

68 that account for either the influence of a single variable on growth, e.g. light exposure (Grima et

69 al., 1994; Huesemann et al., 2013), or the combined influence of multiple variables, such as light,

70 nutrient availability, temperature or pH (Ambrose, 2006; Wolf et al., 2007; Quinn et al., 2011;

71 Broekhuizen et al., 2012; Guest et al., 2013; Decostere et al., 2013; Adesanya et al., 2014; Coppens

72 et al., 2014; Fachet et al., 2014). Although the latter group of models includes more complex

73 approaches, they all show some structural deficiency required to predict the performance of PBRs

74 employed for used water management. The biofilm model PHOBIA (Wolf et al., 2007), for

75 instance, includes the growth of heterotrophs, nitrifiers and microalgae on inorganic carbon, light

76 and nitrogen, but disregards algal growth dependency on phosphate, a key aspect for applications

77 in used water treatment. The model by Broekhuizen et al. (2012) accounts for the effects of pH,

78 inorganic carbon, oxygen, nitrogen, phosphate and light on microalgal growth. However, growth

79 and nutrient uptake are considered directly coupled, and storage of nutrients and growth on the

80 stored nutrients is not considered. To this end, the model by Droop (1973) proposes an approach

81 describing microalgal growth on stored nutrients as well as nutrient uptake and storage. This is an

82 important structural attribute because the calibration of the microbial growth process rate can be 
83 done independently from the process rates identified for nutrient uptake and storage.

84 Consequently, the model can describe growth in the absence of external nitrogen or phosphorus -

85 observed in real system - using the internally stored nitrogen and phosphorus, also referred to as

86 quota (Bernard, 2011). Based on the Droop model, when nutrients are persistently limiting, the

87 minimum internal nutrient quota is gradually reached and the growth rate converges to zero. As

88 for the replenishment of the quota, when nutrients in the bulk medium are available in excess, after

89 the nutrient limitation, the maximum internal quota is reached, thereby reaching the maximum

90 growth rate, at which algal growth becomes independent from the nutrient availability (Bernard et

91 al., 2011). There are several models with multiple substrate limitations in accordance to Droop's

92 approach (Ambrose, 2006; Bernard, 2011; Quinn et al., 2011; Guest et al., 2013; Fachet et al.,

93 2014). Although nitrogen can be stored in the form of amino acids (Romero-García et al., 2012)

94 or nitrate (Coppens et al., 2014), literature is not conclusive about the presence of a possible

95 nitrogen quota for microalgae (Richmond, 2004).

96 Although growth of algae on different organic substrates is well documented (Mata et al., 2010;

97 Brennan and Owende, 2010; Perez-Garcia et al., 2011; Van Wagenen et al., 2015a), none of the

98 above mentioned models combines mixotrophic and heterotrophic growth processes. Moya et al.

99 (1997) propose a simple model for microalgal growth as a function of light (autotrophic growth)

100 and acetate (heterotrophic growth) - the latter expressed using Haldane kinetics. Whilst this

101 approach is useful to predict heterotrophic algal growth in nutrient excess conditions, it does not

102 account for the effects of nitrogen and phosphorus, thereby limiting the model applicability (see

103 e.g. Adesanya et al., 2014).

104 Béchet et al. (2013) propose three different approaches to model the effect of light on algal growth:

105 i) type I: models accounting for an average light intensity and its impact on the algal growth; ii) 
106 type II: models accounting for the light gradient in the PBR and the effect on the photosynthetic 107 rate; and iii) type III: models that consider the photosynthetic rate of an individual algal cell as a 108 function of the light history. The effect of light on algal growth can be modelled by taking into 109 account photo-inhibition using the Steele, Peeters-Eilers and Haldane kinetics (Bouterfas et al., 110 2002; Ambrose, 2006), or omitting the inhibition term using the Monod, Platt-Jassby, Poisson 111 single-hit and Smith models (Bouterfas et al., 2002; Ambrose, 2006; Skjelbred et al., 2012).

112 Design, operation and control of PBRs require process models that are able to predict microalgal 113 growth, as well as the nutrient uptake and storage from used water. Whilst such consensus models 114 already exist for bacterial processes, i.e. the Activated Sludge Models (ASMs) (Henze et al., 2000), 115 for algal systems there is still a lack of a consistent and consensus-based modelling approach. Thus 116 the primary objective of the study is to develop such modelling approach. This is necessary for the 117 development and assessment of operation and control structures for nutrient removal and recovery, 118 which are poorly developed for PBRs, or the generate input data for life cycle assessment studies 119 relevant to PBRs (e.g., Olivieri et al., 2014; Valverde-Pérez et al., 2016; Fang et al., 2015).

120 Proper sets of experiments have to be designed to identify unique sets of model parameters. Whilst 121 optimal experimental design for parameter identification is widely reported for conventional 122 activated sludge models (e.g. Checchi and Marsili-Libelli, 2005; Chandran and Smets, 2005), this 123 aspect has been seldom studied in algal models. Muñoz-Tamayo et al. (2014) reported optimal 124 experimental design to estimate parameters related to algal growth dependence on light and 125 temperature while Decostere et al. (2016) looked into the identifiability of inorganic carbon related 126 parameters using a novel respirometric-titrimetric assay (Decostere et al., 2013). To our 127 knowledge, only one study has dealt with the identifiability analysis of nutrient related parameters 128 (Benavides et al., 2015). However, this study is based on synthetic data generated by simulating 
129 an arbitrary chosen model structure. Therefore, a secondary objective of our study was to design

130 experiments that can be used to infer data to analyse the identifiability and the reliability of the

131 parameter estimates. Consequently, to assess the reliability of the parameter estimates,

132 uncertainties imposed by factors known to affect them in activated sludge models, such as culture

133 history or substrate availability (Grady et al., 1996) should be assessed.

134 The main objectives of the present work are (i) to carry out an exhaustive literature review on

135 process models of algal growth, nutrient uptake and storage; (ii) to identify and evaluate a

136 biokinetic process model - based on the state-of-the-art and using novel formulations of process

137 rate equations - for photoautotrophic and heterotrophic microalgal growth in the ASM framework;

138 (iii) to assess the impact of culture history and substrate availability on parameter estimates and 139 their effects on the accuracy of predicting microalgal growth and nutrient storage; (iv) to assess 140 the model identifiability using data obtained from three different laboratory-scale experimental 141 setups, thereby identifying the sources of parameter variability.

\section{ASM-A MODEL DEVELOPMENT}

\subsection{Modelling in the ASM framework}

144 The systematic model development in this study was carried out as an extension to the well145 established Activated Sludge Model, ASM-2d (Henze et al., 2000). By using the ASM framework, 146 we facilitate the integration of the microalgal model into the existing benchmark models (e.g.

147 Nopens et al., 2010). ASM-2d includes all the bacterial groups involved in enhanced biological 148 phosphorus removal systems (EBPR), i.e. ordinary heterotrophs, nitrifiers and polyphosphate 149 accumulating organisms. The expressions included in this study do not consider the above 150 mentioned bacteria, but only the biochemical processes catalysed by green microalgae (Gujer 151 matrix shown in Table 1). Special attention has been paid to the typical challenges faced when 
152 extending ASM type models (Snip et al., 2014), including: i) units, in accordance with the ASM

153 framework, are expressed in chemical oxygen demand (g-COD), g-N and g-P per cubic metre; and

154 ii) the continuity of the mass balances in the model is checked (Hauduc et al., 2010). To make the 155 integration of the algal model into the existing model structures straightforward, ASM 156 nomenclature (Table 2) was followed (Corominas et al., 2011).

157 Uptake and storage of nitrogen (R1 and R2): ASM-A considers the microalgal uptake and 158 storage of both ammonia (R1) and nitrate (R2) nitrogen (Table 1). The uptake and storage of 159 nitrogen depends on the availability of external nitrogen $\left(S_{N H 4}\right.$ or $\left.S_{N O}\right)$, as well as on the internal 160 cell quota of nitrogen $\left(X_{\text {Alg,N }}\right)$ - the latter being defined as the total intracellularly stored nitrogen. 161 Nitrogen uptake rate decreases as the stored nitrogen approaches the maximum internal cell quota, $162 X_{A l g, N \max }$, in the biomass $\left(X_{A l g}\right)$. Typically, ammonia is preferred over nitrate for most algal species 163 (Cai et al., 2013; Markou et al., 2014). Therefore, a competitive inhibition term by ammonia is 164 included in the nitrate uptake process rate (R2, Table 1).

165 Uptake and storage of phosphorus (R3): The uptake and storage of phosphorus (R3, Table 1) 166 depends on the availability of external soluble orthophosphate ( $\left.S_{P O 4}\right)$, and on the internal cell quota 167 of phosphorus $\left(X_{A l g, P P}\right)$ - the latter being defined as the total intracellularly stored phosphorus. 168 Accordingly, the phosphorus uptake rate decreases as the stored phosphorus approaches the 169 maximum internal cell quota, $X_{\text {Alg,PPmax. }}$

170 Photoautotrophic growth (R4): Nutrient limitations are described according to Droop (1973).

171 The specific growth rate decreases as the internal cell quota approaches the minimum internal 172 quota $\left(X_{A l g, N m i n}\right.$ or $\left.X_{A l g, P P \min }\right)$. The consumption of inorganic carbon $\left(S_{A l k}\right)$ is modelled using Monod 173 kinetics. Light limitation is determined by the photo-synthetically available irradiance passing 
174 through the PBR. In this study, we assume that the microalgae are exposed to a constant average

175 light intensity (type I light model, Béchet et al., 2013), denoted as $I_{A v}$. To identify a suitable model

176 structure that describes the light influence on microalgal growth, six different model equations

177 were fitted to the obtained experimental data. Light dependence is modelled using the Steele

178 equation, which was identified through an extensive model discrimination exercise using

179 experimental results (section 4.1.1).

180 The COD mass-balance cannot be closed for the photoautotrophic microalgal growth, which is 181 explained as follows. During the photophosphorilation, algae produce the energy needed for

182 carbon fixation through the Calvin cycle and release oxygen as a by-product. In addition, the 183 energy produced can also be used to build macromolecules (e.g. lipids or starch), to assimilate 184 nitrate, etc. (Wilhelm and Jakob, 2011). The energy not used via the Calvin cycle yields to a higher 185 oxygen production without contributing to biomass production (i.e. COD production), and thus 186 preventing the mass-balance to be closed. Since carbon dioxide, light and water, the substrates in 187 this process do not contribute to the COD balance, they cannot be used either to close the balance. 188 Therefore, the stoichiometry for photoautotrophic growth is set according to literature (Park and 189 Craggs, 2011), and, in this case, the continuity check is only used to close the mass balances for $\mathrm{N}$ 190 and $\mathrm{P}$.

191 Heterotrophic algal growth (R5): Acetate is used as the organic carbon substrate $\left(S_{A}\right)$, state192 variable included in the ASM-2d. The Monod kinetics is used to model the heterotrophic growth 193 as a function of the substrate concentration. Oxygen serves as a terminal electron acceptor for 194 heterotrophic growth (So2), and its effect is modelled by Monod kinetics. Inhibition of the 195 heterotrophic growth by light intensity is modelled using the competitive inhibition term. The 
196 nutrient consumption associated with algal growth is included analogously to that described in the 197 photoautotrophic growth.

198 Algal decay (R6): The algal decay process rate includes the internal resources used for

199 maintenance, biomass loss during dark respiration and death and lysis that reduces the amount of 200 active biomass in the culture. In addition, the term includes reduction in biomass due to predators 201 grazing on the algal biomass. The decay process is modelled following the dead-regeneration 202 principle, which states that a fraction of the products from decay become available for microbial 203 growth (van Loosdrecht and Henze 1999).

\subsection{Limitations of the model}

205 ASM-A was identified using experimental data inferred using synthetic growth medium. 206 Conversely, in real systems, factors related to light attenuation (e.g., chromophores) and toxicity 207 (e.g., pharmaceutical residues), occurring in (treated) used water can significantly influence 208 growth conditions that the present model and its calibration do not account for and future model 209 identification studies should quantify them. Furthermore, although the model is implemented as 210 an extension of the ASM-2d and predicts bacterial growth and some interactions between bacteria 211 and algae (e.g. support of heterotrophic bacterial growth via oxygen supply from the algae), direct

212 interactions between algal and bacterial growth, are not considered in this study, and bacterial 213 processes are assumed negligible during the experiments. Further details about how bacterial-algal 214 interactions are accounted for by means of the ASM-A model are described in the Supporting 215 Information (SI, pages S29-S31).

216 High oxygen levels can cause photo-oxidative damage on microalgae (Muñoz and Guieysse, 217 2006). Photo-oxidative damage caused by elevated $\mathrm{O}_{2}$ levels is reported at significantly higher 
218 levels of oxygen in the liquid phase (e.g. $24.5 \mathrm{mg} \mathrm{O}_{2} \cdot \mathrm{L}^{-1}$ reported in Alcántara et al., 2013) than

219 that observed in our study $\left(10 \mathrm{mg} \mathrm{O} \cdot \mathrm{L}^{-1}\right)$, and mostly it occurs in photobioreactors with poor

220 mixing. This can be avoided with adequate mixing as was the case in our study. The effect of $\mathrm{O}_{2}$

221 inhibition thus could not be measured, and targeted experiments should be done - in the future -

222 to extend the application of the model to account for photo-oxidative inhibition during autotrophic

223 algal growth. Elevated organic carbon content can potentially inhibit autotrophic microalgal 224 growth (Alcántara et al., 2013). Van Wagenen et al. (2015b) reported no decrease in 225 photoautotrophic growth and nutrient removal in the presence of sufficient light intensity and up 226 to $400 \mathrm{mg} \cdot \mathrm{L}^{-1}$ volatile fatty acids (VFA). This concentration is significantly higher than what is 227 expected in effluents from domestic wastewater treatment systems (Tchobanoglous et al., 2004).

228 Therefore, we contend that autotrophic growth inhibition by VFAs can be ignored.

229 The charge balances have not been tracked through model development. Hauduc et al. (2010) 230 suggest using alkalinity as a sink to close charge balance, leading to stoichiometric coefficients 231 that disregard the biological processes. In the future, the charge balance should be closed using 232 methods for pH estimation (e.g. Flores-Alsina et al., 2015), thereby achieving more accurate 233 estimation of the carbon speciation which might additionally affect microbial growth rates 234 (Decostere et al., 2013). Moreover, the model currently does not consider temperature effects on 235 model parameter values, which is particularly important when considering open pond type 236 systems. This must be addressed in next model generations. 


\section{MATERIALS AND METHODS}

\subsection{Microalgae and culture media}

242 The mixed green microalgal consortium used in this study was isolated in a natural pond in contact

243 with used water. The culture mainly consists of Chlorella sorokiniana (identification made by the

244 PCR method after isolation of the species as described in the SI, page S24, Fig. S1, SI) and

245 Scenedesmus sp. (based on microscopic observations, Fig. S2, SI). The algal culture grows strictly

246 in suspension, without significant biofilm or aggregate formation. The mixed culture was

247 cultivated using the MWC+Se synthetic medium (Guillard and Lorenzen, 1972), unless otherwise 248 specified.

\subsection{Experimental design and description of the reactors}

\subsubsection{Microbatch experiments}

251 Microbatch experiments were set up in 24-well black microtiter plates (VisiPlate, PerkinElmer

252 Inc., Waltham, MA) in a temperature controlled room at $20{ }^{\circ} \mathrm{C}$. The microbatches - placed on a

253 shaker table operated at $160 \mathrm{rpm}$ - were inoculated with $2 \mathrm{~mL}$ samples with $14 \mathrm{mg} \mathrm{NO}_{3}^{-}-\mathrm{N} \cdot \mathrm{L}^{-1}$

254 and $1.55 \mathrm{mg} \mathrm{PO}-\mathrm{P} \cdot \mathrm{L}^{-1}$. Thereby, nutrients were available in excess in the medium. The light was

255 supplied by cool white LEDs (Werner Co., USA).

256 To assess the effect of light intensity on the microalgal growth, neutral density filters were attached

257 to the bottom of the microbatches to create different light intensities (Van Wagenen et al., 2014).

258 Two sets of experiments were carried out, resulting in twelve different light intensities ranging 259 from 12 to $870 \mu \mathrm{mol}$ photons $\mathrm{m}^{-2} \mathrm{~s}^{-1}$.

260 In addition, microbatch experiments were set up to assess the heterotrophic growth of microalgae

261 in darkness. The MWC+Se culture medium was modified by adding acetate as organic carbon 
262 supplied at different concentrations $\left(10-1000 \mathrm{mg} \cdot \mathrm{L}^{-1}\right)$. The cultures were grown on the same shaker 263 table, and kept in complete darkness (Van Wagenen et al., 2015a). Moreover, two sets of 264 measurements at two different light intensities $\left(120 \mu \mathrm{mol}\right.$ photons $\mathrm{m}^{-2} \mathrm{~s}^{-1}$ and $450 \mu \mathrm{mol}$ photons $\left.265 \mathrm{~m}^{-2} \mathrm{~s}^{-1}\right)$ were conducted to assess the effect of light intensity on the acetate uptake rate $\left(200 \mathrm{mg} \cdot \mathrm{L}^{-}\right.$

$266{ }^{1}$ acetate in each well) and heterotrophic growth. At each measurement point, the algal biomass 267 was measured and the content of three wells were removed and prepared for acetate measurement. 268 This method allowed us to monitor the growth rate together with the acetate removal rate in the 269 microbatch scale.

\subsubsection{Sequenced batch experiments in 1-L PBRs}

271 Batch experiments were set up using 1-L wide-neck glass bottles (Duran ${ }^{\circledR}$, Germany) with constant 272 stirring at $180 \mathrm{rpm}$ using magnetic stirrers and with a multi-port system, allowing for sample 273 extraction and aeration with $\mathrm{CO}_{2}$ enriched air $\left(5 \% \mathrm{CO}_{2}\right)$ at a flow rate of $10 \mathrm{~L} \cdot \mathrm{h}^{-1}$. pH was kept 274 between 6.5-8. Light was supplied from the two sides of the batches using 18-W fluorescent lamps 275 (GroLux, Sylvania ${ }^{\circledR}$, USA), providing $160 \mu \mathrm{mol}$ photons $\mathrm{m}^{-2} \mathrm{~s}^{-1}$ continuously. Three parallel batch 276 reactors were run where the nitrogen source in one was ammonium while in the others nitrate. The initial 277 concentration of nutrients was varied by decreasing the nitrogen (either ammonium or nitrate) or 278 phosphorus levels 3 times. Initial nitrogen and phosphorus concentrations ranged between 0.3-14 $279 \mathrm{mg} \cdot \mathrm{L}^{-1}$ as $\mathrm{N}$ and $0.1-1.55 \mathrm{mg} \cdot \mathrm{L}^{-1}$ as $\mathrm{P}$, respectively. Microalgal biomass was diluted when optical 280 density (OD) reached a value of 0.4 (corresponding to $0.21 \mathrm{~g} \mathrm{TSS} \cdot \mathrm{L}^{-1}$, Fig. S3). $90 \%$ of the volume 281 was replaced with fresh cultivation medium thereby avoiding self-shading in the culture (and thus 282 light limitation). Temperature was kept constant in the room at $20^{\circ} \mathrm{C}$. During the batch experiments 283 the limiting and the non-limiting nutrients as well as cell density were monitored. 
284 Heterotrophic growth and the acetate uptake were assessed in 1-L batches under dark conditions 285 at $20^{\circ} \mathrm{C}$ with concentration of $14 \mathrm{mg} \mathrm{NO}{ }_{3}^{-}-\mathrm{N} \cdot \mathrm{L}^{-1}$ and $1.55 \mathrm{mg} \mathrm{PO}{ }_{4}-\mathrm{P} \cdot \mathrm{L}^{-1}$, ensuring nutrients to be 286 in excess. Initial acetate concentrations were set to 200 and $400 \mathrm{mg} \cdot \mathrm{L}^{-1}$. Constant air was supplied 287 to the cultures to avoid limitation by oxygen and the batches were kept in complete darkness.

\subsubsection{Sequential batch experiments in 24-L PBRs}

289 Experimental data were collected for model calibration and validation in a 24 L laboratory-scale 290 airlift PBR. In the first four cycles (Descending cycles), the initial ammonia and nitrate 291 concentration decreased in sequential cycles from 10 to 5 to 2.5 to $0.5 \mathrm{mg}-\mathrm{N} \cdot \mathrm{L}^{-1}$. In the following 292 four cycles (Ascending cycles), the initial ammonia and nitrate concentration increased from 0.5 293 to 2.5 to 5 to $10 \mathrm{mg}-\mathrm{N} \cdot \mathrm{L}^{-1}$ (Fig. 1). Each cycle was run once in a consecutive manner. The reactor 294 was operated with constant aeration with $\mathrm{CO}_{2}$ enriched air $\left(5 \% \mathrm{CO}_{2}\right)$ with $600 \mathrm{~mL} \cdot \mathrm{min}^{-1}$ flow rate. $295 \mathrm{pH}$ varied between 6.2-7. The temperature varied between $17-21{ }^{\circ} \mathrm{C}$. A custom-built lamp, 296 providing $600 \pm 50 \mu$ mol photons $\mathrm{m}^{-2} \mathrm{~s}^{-1}$, with two metal-halide light bulbs (OSRAM ${ }^{\odot}$, Germany), 297 was placed on top of the reactor.

\section{$<$ Figure 1 $>$}

\subsection{Analytical methods}

300 In-vivo fluorescence (IVF) at $440 \mathrm{~nm}$ excitation and $690 \mathrm{~nm}$ emission was used to measure and 301 estimate directly the algal growth in microplates due to its high sensitivity at low biomass 302 concentrations (Van Wagenen et al., 2014). Acetate was measured using HPLC (Van Wagenen et 303 al., 2015a). Biomass in the 1-L and 24-L batch reactors was analysed by measuring the OD at 750 $304 \mathrm{~nm}$ and by total suspended solids (TSS) measurement using glass fibre filter (Advantec ${ }^{\circ}$, USA) 305 with a pore size of $0.6 \mu \mathrm{m}$ (APHA, 1995). TSS units were converted to COD using a conversion 
306 factor of 0.72 gTSS/gCOD (estimated as explained in the SI).Total nitrogen and phosphorus

307 measurements in the suspension were done using commercial test kits (Hach-Lange ${ }^{\odot}$, USA).

308 Following sample filtration $(0.2 \mu \mathrm{m}$ filter $)$, ammonium, nitrate, nitrite and phosphate

309 concentrations were measured using test kits supplied by Merck $^{\odot}$ (USA). The internal cell quota

310 of nitrogen was calculated based on the difference of total nitrogen in the algal suspension

311 (algae+medium) and total soluble nitrogen in the filtrate (soluble organic $\mathrm{N}, \mathrm{NH}_{4}{ }^{+}, \mathrm{NO}_{2}{ }^{-}$and $\mathrm{NO}_{3}{ }^{-}$

312 ). The internal cell quota of phosphorus was obtained by the difference of total phosphorus in the

313 algal suspension and soluble phosphate in the filtrate.

$314 \quad$ 3.4.Model implementation and calibration

$315 \quad$ 3.4.1. Calibration procedure for $1-\mathrm{L}$ and $24-\mathrm{L}$ batch experiments

316 A model identifiability analysis was carried out to determine if the information gathered from the

317 1-L and 24-L batches was rich enough, both quantitatively and qualitatively, to estimate

318 parameters. The methodology developed, adapted from literature, is referred to as the Latin

319 Hypercube Sampling based Simplex (LHSS). It comprises 5 modular steps (Fig. 2): Step 1: the

320 parameter space for the parameters to be estimated in each experiment is defined, based on the

321 extensive literature review presented in section 2.1; Step 2: Latin Hypercube Sampling (LHS,

322 Helton and Davis, 2003) is used to select values from the parameter space; Step 3: the parameter

323 sets are used as initial values (a priori) for the local optimization algorithm, Simplex (Nelder and

324 Mead, 1965). The objective function to be minimized is the root mean square normalized error

325 (RMSNE) relative to the measured value $\left(y_{m}\right)$ :

326

$$
R M S N E=\sqrt{\frac{1}{n} \sum_{i=1}^{n}\left(\frac{y_{m}-y}{y_{m}}\right)^{2}}
$$

327 where $n$ is the number of measurement points, and $y$ is the predicted value. 
328 Simplex can identify different optimal parameter sets. Step 4: Thresholds are set by visualization

329 of the distribution of the RMSNE (histogram) for the estimated parameter subsets resulting in

330 different cut-off values in the two scales (1\% and $10 \%$ of the minimum RMSNE, Fig. S4, SI).

331 Parameter subsets resulting in an error higher than these thresholds are considered as local minima

332 and omitted in further steps; Step 5: The distribution of the optimal parameter set values obtained

333 through Simplex, combined with the average parameter values, standard deviations and correlation

334 matrix are used for identifiability assessment. The distributions of parameter value estimates are

335 plotted as histograms that are interpreted according to their relative wideness, i.e. the narrower the

336 histogram, the more identifiable the parameter is (Van Daele et al., 2015). Parameter

337 identifiability, in this step, is assessed by additionally considering the standard deviations and the

338 correlation matrix, as suggested by Sin et al. (2010). Based on the correlation matrix, if the

339 correlation of parameters is comparably high, then the parameter identifiability should be assessed

340 by analysing the impact of setting one of the parameters to its minimum and maximum boundaries

341 defined by the standard deviation on the simulation output. The Janus coefficient $(J)$ is used to

342 assess the difference in model predictions (Sin et al., 2007). The Janus coefficient describes the

343 accuracy of the model prediction, and for reliable predictions its value is close to 1 . Janus

344 coefficients higher or lower than 1 indicate that predictions are worse or better than the original

345 model approximations obtained through parameter estimation, respectively. We find that 500 LHS

346 samples are sufficient to reach convergence on the parameter distributions.

$<$ Figure 2>

\subsubsection{Autotrophic growth model calibration}

349 Specific growth rates were obtained as a function of light intensity using microplate experimental

350 data. Six different expressions (specified in the model development section), describing the effect 
351 of light on algal growth, were tested by approximating the experimental data. Parameter values for

352 the maximum photoautotrophic growth rate $\left(\mu_{A, \max }\right)$ and the saturation light intensity $\left(I_{S}\right)$ were

353 obtained from the fitting.

$354 X_{A l g, N \max }, X_{A l g, N m i n}, X_{A l g, P P \max }$ and $X_{A l g, P P \min }$ were approximated as the observed maximum and 355 minimum quota reached overall in the 1-L and 24-L sequenced batch experiments. The 356 stoichiometric parameters, nitrogen and phosphorous content of algal biomass ( $i_{\text {Nxalg }}$ and $i_{\text {Pxalg }}$ )

357 were set as the minimum observed quota of nitrogen and phosphorus. Parameter values for $\mu_{A, \max }$ 358 and half saturation coefficients of ammonium $\left(K_{N H 4, A l g}\right)$, nitrate $\left(K_{N O, A l g}\right)$ and phosphate $\left(K_{P O 4, A l g}\right)$

359 and the maximum specific uptake rates of ammonium $\left(k_{N H 4, A l g}\right)$, nitrate $\left(k_{N O, A l g}\right)$ and phosphate $360\left(k_{P O 4, A l g}\right)$ were obtained in the 1-L batches with the LHSS parameter estimation method. Microalgal 361 decay rate $\left(b_{X a l g}\right)$ was set at $2 \% * \mu_{\mathrm{A}, \max }$ as suggested by Quinn et al. (2011).

362 Parameters $\mu_{\mathrm{A}, \mathrm{max}}, K_{\mathrm{NO}, \mathrm{Alg}}, K_{\mathrm{NH} 3, \mathrm{Alg}}, K_{P O 4, \mathrm{Alg}}, k_{\mathrm{NO}, \mathrm{Alg}}, k_{N H 3, A l g}, k_{P O 4, A l g}$ and $b_{X a l g}$ were also estimated 363 using the experimental data obtained using the 24-L reactor setup. Average light intensity was set 364 in each cycle, calculated based on Benson et al. (2007), i.e. by integrating the Lambert-Beer 365 equation over the culture depth. The parameter estimates used to calibrate the Lambert-Beer 366 equation are those presented by Wágner et al. (2014).

\subsubsection{Heterotrophic growth model calibration}

368 The Monod kinetics was fitted on the results obtained in microbatch experiments. Data obtained 369 in 1-L batch experiments were used to estimate kinetic parameters using the LHSS method. 370 Parameter values for minimum and maximum quotas, half saturation coefficients and maximum 371 specific uptake rates of $\mathrm{N}$ and $\mathrm{P}$ are taken from the autotrophic growth process rate. Parameter 372 values for the maximum heterotrophic growth rate $\left(\mu_{H, \max }\right)$ and the half saturation coefficient of 
373 acetate $\left(K_{A}\right)$ were estimated using data obtained in the microbatch and 1-L batch experiments. The

374 observable yield on acetate $\left(Y_{A C}\right)$ was calculated from the 1-L batch experiments as the ratio of $g$

375 biomass produced as COD and g acetate consumed as COD.

376 In the presence of light and acetate, we observe mixotrophic growth. To assess the effect of light

377 on heterotrophic growth kinetics (described in section 3.2.1), we calculated the heterotrophic

378 biomass production based on the acetate consumption in the microbatch experiments. The

379 observed value of $\mu_{H, \max }$ was estimated using the data from the exponential growth phase for both

380 light intensities using the estimated heterotrophic biomass production. The value of the half-

381 saturation coefficient for light inhibition $\left(K_{I}\right)$ was estimated by approximating the observed $\mu_{H, \max }$

382 at different light intensities from the microbatch experiments, including $\mu_{H, \max }$ estimated in 1-L

383 batch in darkness, using the competitive inhibition term.

\subsubsection{Literature values}

385 Remaining model parameters were taken or calculated based on literature (specified in Table 3).

386 In ASM-A, the half-saturation coefficient of inorganic carbon $\left(K_{A l k}\right)$ is according to Broekhuizen

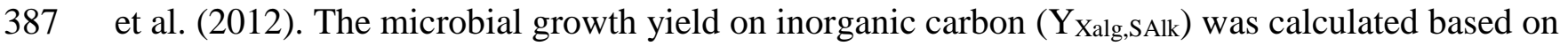

388 the stoichiometry presented in Park and Craggs (2011). The half-saturation coefficient for oxygen

$389\left(K_{O 2}\right)$ in the heterotrophic growth is based on the minimum operational oxygen level reported in

390 literature, and is given as $20 \%$ of the saturation oxygen concentration (Morales-Sánchez et al.,

391 2013). The inert fraction of the biomass $\left(f_{X I}\right)$ produced via decay is accounted for according to

392 Henze et al. (2000). The nitrogen and phosphorus released during the decay process in the form of 393 inert and biodegradable matter ( $i N_{\text {XalgI }}, i N_{\text {Xalgs, }} i P_{\text {XalgI }}$ and $\left.i P_{\text {Xalgs }}\right)$ is based on Henze et al. (2000).

\section{$394 \quad$ 3.4.5. Model implementation}


395 The ASM-A model was developed as an extension of the simulation model ASM-2d (Henze et al.,

396 2000), which was implemented in Matlab (The MathWorks, Natick, MA; Flores-Alsina et al.,

397 2012). The Matlab solver ode15s was used (see e.g. Flores-Alsina et al., 2012).

\subsection{Model evaluation}

399 The experimental design developed for the 24-L sequenced batch PBR (Fig. 1) was used through

400 a two-step model evaluation. To this end, the hypothesis tests set for the two model evaluation

401 steps comprise the questions (I) Do culture history and/or substrate availability significantly

402 influence parameter estimates?; (II) What are the practical consequences for model calibration?,

403 i.e. can we use a mean parameter set to accurately predict algal cultivation in PBRs?; (III) Can we

404 explain inaccuracies as a result of parameter variability? To answer hypothesis-I, it is noteworthy

405 that the experimental design (Fig. 1) used with different initial substrate to biomass ratio in each

406 cycle allows decoupling the culture history from the substrate availability impact. Through the

407 first evaluation step, parameter sets obtained through each descending cycle (Table 4) were

408 confronted with data obtained in the corresponding (same initial substrate concentrations)

409 ascending cycle (Fig. 1). To assess model accuracy, we used the Janus coefficient (Sin et al., 2007).

410 To answer hypothesis-II and III, in the second evaluation step, Monte Carlo simulations were

411 performed to obtain a confidence interval of model predictions (Sin et al., 2009). The probability

412 range of ASM-A parameters was assigned by calculating the minimum/maximum parameter

413 values as the mean estimated parameter values minus/plus the standard deviation, respectively.

414 The mean and standard deviation values were calculated through the initial descending cycles

415 (Table 3). The uncertainty classes were assigned to each parameter based on previous knowledge,

416 as suggested by Sin et al. (2009), and are reported in Table S2. 
417 For those state-variables that failed both evaluation steps global sensitivity analysis (GSA) was

418 carried out. The GSA method applied in this study is linear regression of Monte Carlo simulations

419 (Saltelli et al., 2008) - also referred to as the standard regression coefficient (SRC) method (more

420 details on the method are present in the SI, pages S27-S28). Only the parameters for which $\beta_{\mathrm{i}} \geq$

4210.1 are considered to be influential (Sin et al., 2011). In this study, 1000 Monte Carlo simulations

422 are found to be sufficient to achieve convergence.

\section{RESULTS AND DISCUSSION}

\section{4.1. Model identification}

\section{4.1.1. Autotrophic growth}

426 The Steele expression (included in R4) was found to most accurately $\left(\mathrm{R}^{2}=0.995\right)$ describe the light

427 dependence of algal growth (Table S3, SI; Fig. 3). We note, however, that the $\mathrm{R}^{2}$ obtained with all 428 six expressions is comparably high, i.e. $\mathrm{R}^{2}>0.99$. The Steele equation accounts for the photo429 inhibition on algal growth, a factor not fully supported by the measured data, and hence, further 430 assessment at higher light intensities is necessary to understand better the inhibition by light. In 431 full-scale systems, however, the prevalence of such high average light intensity ( $>900 \mu \mathrm{mol} \mathrm{m}^{-2} \mathrm{~s}^{-}$ $432{ }^{1}$ ) is assumed to be negligible. The estimated values for $\mu_{A, \max }$ and $I_{s}$ are $3.6 \pm 0.04 \mathrm{~d}^{-1}$ and $758 \pm 23$ $433 \mu \mathrm{mol} \mathrm{m} \mathrm{m}^{-2} \mathrm{~s}^{-1}$, respectively (Table 3). It should be noted that we used observed growth rates to 434 calibrate phototrophic growth, disregarding the effect of the decay rate. Therefore, the maximum 435 growth rate may be underestimated. 
438 According to the microbatch experimental results, for $\mathrm{S}_{\mathrm{A}}=0-180 \mathrm{mg} \mathrm{COD} \cdot \mathrm{L}^{-1}$, heterotrophic 439 growth can be effectively described using the Monod expression (suggested by Turon et al. (2015)) 440 (Fig. S5, SI). The approximation of the experimental data $\left(\mathrm{R}^{2}=0.7\right)$ results in $\mu_{H, \max }=0.7 \pm 0.06 \mathrm{~d}^{-1}$ 441 and $K_{A}=10.7 \pm 3.6 \mathrm{~g} \mathrm{COD} \cdot \mathrm{m}^{-3}$ (Table 3). We note that our measurements show a plateau (Fig. S5, 442 SI) - with growth rates around $0.38 \mathrm{~d}^{-1}-$ above approx. $180 \mathrm{mg} \cdot \mathrm{L}^{-1}$ acetate concentration. Species 443 that are capable of growing under both heterotrophic and photoautotrophic conditions are reported 444 to have similar heterotrophic and photoautotrophic growth rates (Ogawa and Aiba, 1981; Van 445 Wagenen et al., 2015a) - as opposed to our case. The value of $\mu_{A, \max }$ is significantly higher than 446 that obtained for $\mu_{H, \max }$ (i.e. $\mu_{A, \max }=3.6 \pm 0.04 \mathrm{~d}^{-1}$ and $\mu_{H, \max }=0.7 \pm 0.06 \mathrm{~d}^{-1}$ ). However, when 447 microbatches with acetate were exposed to different light intensities, the observed $\mu_{H, \max }$ is 448 comparably higher (i.e. $2.8 \pm 0.8 \mathrm{~d}^{-1}$ and $2.14 \pm 0.6 \mathrm{~d}^{-1}$ ). Under mixotrophic growth conditions, the 449 oxygen needed to support heterotrophic growth in microbatch experiments is overcompensated by 450 the oxygen produced during the autotrophic growth. Therefore, it is suggested that heterotrophic 451 microbatch experiments were limited by the oxygen level, thereby decreasing the observed $\mu_{H, \max }$ 452 (i.e. $0.7 \pm 0.06 \mathrm{~d}^{-1}$ ). It is also hypothesised that the plateau observed in Fig. S5 ( $\mu$ around $0.38 \mathrm{~d}^{-1}$ ) 453 is caused by the inefficient oxygen transfer in the microplates.

454 The kinetic parameters obtained from the measurements conducted in 1-L batches (Fig. S6a, SI) 455 are the heterotrophic growth on acetate and the affinity coefficient for acetate, i.e. $\mu_{H, \max }=4.5 \pm 0.05$ $456 \mathrm{~d}^{-1}$ and the $K_{A}=6.3 \pm 0.52 \mathrm{gCOD} \cdot \mathrm{m}^{-3}$. The estimated parameters were evaluated using an 457 independent set of experimental data (Fig. S6b, SI), and results obtained show low discrepancy 458 between measured and simulated data (J 1, Table S4, SI). However, the value of $\mu_{H, \max }$ obtained 459 at this scale is significantly higher than that obtained in the microbatch experiments $460\left(\mu_{H, \max }=0.7 \pm 0.06 \mathrm{~d}^{-1}\right)$. Since 1-L batch reactors were continuously aerated, oxygen was not 
461 limiting heterotrophic growth. Typical values of COD measured in influent domestic used water 462 are in the range of $250-800 \mathrm{mg} \cdot \mathrm{L}^{-1}$ (Tchobanoglous et al., 2004). Thus in used water treatment 463 processes acetate and other volatile fatty acids are not expected to inhibit heterotrophic growth. $464 Y_{A C}$ was calculated to be $0.42 \mathrm{gCOD} \cdot \mathrm{g}^{-1} \mathrm{COD}$ (Table 3 ) from the 1-L batch experiments. $K_{I}$ was 465 determined using measured data inferred in both microbatch (mixotrophic growth, at two different 466 light intensities) and 1-L batch experiments (heterotrophic growth, no light), estimated to be $467331 \pm 160 \mu \mathrm{mol} \mathrm{m}^{-2} \mathrm{~s}^{-1}$ (Fig. 4). Due to the low experimental data considered in this study, $\mathrm{K}_{\mathrm{I}}$ should 468 be interpreted with caution.

\subsubsection{Nutrient uptake and storage}

471 The kinetic parameters were estimated using the LHSS method (Step 1-3, Fig. 2) using data 472 obtained in the 1-L batch experiments, resulting in $\mu_{A, \max }=3.54 \pm 0.05 \mathrm{~d}^{-1}, K_{N H 3, A l g}=6.7 \pm 1.63 \mathrm{gN} \cdot \mathrm{m}^{-}$ $473{ }^{3}, K_{N O, A l g}=6.87 \pm 2.56 \mathrm{gN} \cdot \mathrm{m}^{-3}, K_{P O 4, A l g}=4.71 \pm 0.65 \mathrm{gP} \cdot \mathrm{m}^{-3}, k_{N H 3, A l g}=2.55 \pm 0.61 \mathrm{gN} \cdot \mathrm{m}^{-3}, k_{N O, A l g}=$ $4742.13 \pm 0.86 \mathrm{gN} \cdot \mathrm{m}^{-3}$ and $k_{P O 4, A l g}=4.84 \pm 0.67 \mathrm{gP} \cdot \mathrm{m}^{-3}$ (Table 3). The specification of the experimental 475 data that are used to calculate the objective function in each of the 1-L batch experiments is 476 included in the supporting information (Table S5). Initial conditions for the 1-L and 24-L batch 477 experiments are reported in the supporting information (Table S6). The upper and lower 478 boundaries of the LHSS simulations are included in the supporting information in Table S7. In 479 accordance with the standard deviations of the parameter values (for $\mu_{A, \max }$, the average standard 480 deviation is $1.5 \%$, and for uptake rates and affinity coefficients it is below 40\%), the histograms 481 (Table S8, SI) show a relatively narrow parameter distribution, thereby indicating that the 482 parameters are identifiable (Step 5, Fig. 2). The low standard deviation obtained can be attributed 
483 to the fact that parameter estimation was carried out by omitting measurement noise. The cut-off 484 value of $1 \%$ is set as a general threshold for local minima rejection (Step 4, Fig. 2) in all three 485 experiments (Table S8, Fig. S4a, S6b, SI). This included more than 70\% of the parameter sets in 486 the ammonium and phosphorus limiting 1-L batches (Table S8, SI). However, in the nitrate batch, 487 as a result of the high number of local minima identified and rejected (Fig. S4a, SI), even though 488 convergence was reached in the RMSNE distribution, only approx. 15\% of the parameter sets were 489 included in the 1\% range. Based on the correlation matrix, the parameters can be considered highly 490 correlated, i.e. the matrix elements are close to 1 (Table S8, SI). Therefore, we further assessed the 491 impact of the parameter variability on the model output (Step 5, Fig. 2). To this end, we compared 492 the simulation results using parameter values on the boundaries given by their standard deviation. 493 We show one example (Fig. S7, SI), where we altered one parameter that is highly correlated with 494 another (in this case we alter $k_{N O, A l g}$ that is correlated with $K_{N O, A l g}$ ). We set $k_{N O, A l g}$ to its maximum 495 and minimum value (i.e. mean \pm standard deviation), and the effect of this manipulation was 496 assessed using the simulation outputs (including algal biomass concentration, soluble nitrate 497 concentration and nitrogen storage). We found comparably low variation in the model outputs 498 when altering $k_{N O, A l g}$ (Janus coefficient $\sim 1$, Fig. S7, SI). This approach was also employed to test 499 all experimental data (Table S8, SI) and all highly correlated parameters. The discrepancies 500 obtained between the outputs are comparably low in all cases (Janus coefficients 1, not shown; 501 Step 5, Fig. 2), thus suggesting parameters are identifiable. The minimum and maximum nitrogen 502 content observed throughout these experiments are $X_{A l g, N m i n}=0.012 \pm 0.003 \mathrm{gN} \cdot \mathrm{g}^{-1} \mathrm{COD}$ and $503 X_{\text {Alg,Nmax }}=0.09 \pm 0.004 \mathrm{gN} \cdot \mathrm{g}^{-1} \mathrm{COD}$, respectively. The minimum and maximum phosphorus content 504 measured throughout these experiments are used as minimum and maximum quotas in the final 505 model calibration set, i.e. $X_{\text {Alg,PPmin }}=0.0021 \pm 0.0005 \mathrm{gP} \cdot \mathrm{g}^{-1} \mathrm{COD}$ and $X_{\text {Alg,PPmax }}=0.019 \pm 0.0006$ 
$506 \mathrm{gP} \cdot \mathrm{g}^{-1} \mathrm{COD}$, respectively (Table 3). Any phosphorus content above this minimum quotum is 507 referred to as "phosphorus storage" for the algae, which can include polyphosphate (Powell et al., 508 2008).

509 Experiments assessing the effect of nutrient limitation on microalgal growth were conducted in a 510 24-L batch reactor (Fig. 5; Fig. S8-S10, SI). The lowest and highest levels of nitrogen quota found 511 are $X_{\text {Alg,Nmin }}=0.00936 \pm 0.002 \mathrm{gN} \cdot \mathrm{g}^{-1} \mathrm{COD}$ and $X_{\text {Alg,Nmax }}=0.13 \pm 0.016 \mathrm{gN} \cdot \mathrm{g}^{-1} \mathrm{COD}$, respectively

512 (Table 3), which are included as the minimum and maximum quotas in the model calibration 513 exercise as final parameter values. Any nitrogen content above this minimum quotum is referred 514 to as "nitrogen storage” for the algae, which can be in different forms (Romero-García et al., 2012; 515 Coppens et al., 2014). The minimum and maximum phosphorus content observed throughout the 516 24-L batch experiments are $X_{A l g, P P \min }=0.0028 \pm 0.0006 \mathrm{gP} \cdot \mathrm{g}^{-1} \mathrm{COD}$ and $X_{A l g, P P \max }=0.016 \pm 0.0006$ $517 \mathrm{gP} \cdot \mathrm{g}^{-1} \mathrm{COD}$, respectively, which were within the range found for the 1-L batch data. The affinity 518 coefficients, $K_{N H 4, A l g}, K_{N O, A l g}$ and $K_{P O 4, A l g}$ and the uptake rates, $k_{N H 4, A l g}, k_{N O, A l g}$ and $k_{P O 4, A l g}$ were 519 estimated to evaluate and possibly validate the values obtained using the 1-L batch data. We 520 assumed that, in the 24-L batch experiments, the culture was exposed to an average light intensity 521 (estimated for each of the batches - Table S9, SI) in the PBR and that there was no inorganic 522 carbon limitation. Additionally, the RMSNE values obtained through parameter estimation are 523 presented in Table 5. Based on experimental data obtained in the 1-L and 24-L batches (Table 3), 524 a comparative assessment of parameter estimates was carried out, indicating significant 525 discrepancy for only nutrient uptake process rate parameters, i.e. $k_{N H 4, A l g}, k_{N O, A l g}$ and $k_{P O 4, A l g}$ (up to 526 50-times difference). This discrepancy could be explained as a consequence of the different 527 hydrodynamics of the batch reactors. That is, 1-L reactors are well mixed by a magnetic stirrer and 528 bubbling. However, the 24-L reactor mixing only relies on the advective flow induced by the 
529 bubbling in the inner side of the reactor. Therefore, there is a higher chance to induce dead zones

530 in the second reactor. Poor mixing has been reported to affect parameter estimates, showing

531 apparent slower dynamics (Arnaldos et al., 2015). Moreover, the discrepancy may be due to the

532 lack of accounting for the impact of light attenuation under dynamic conditions along the

533 experiment in the 24-L PBR. Additionally, the lack of temperature control in the in the 24-L batch

534 reactors resulted in oscillating temperatures below $20{ }^{\circ} \mathrm{C}$ during the experiments. The lower

535 temperature may have caused reduced microbial activity (Ras et al., 2013) that could have

536 contributed to the discrepancy between the parameter values.

\section{$<$ Figure 5 $>$}

538 In an effort to benchmark parameter values obtained herein, literature values (Table S2, SI)

539 selected from studies focusing on Chlorella sp. and/or Scenedesmus sp. were used. A close

540 agreement is found between parameter values estimated in this study and those in literature - also

541 the case for nutrient uptake rates ( $k_{N H 4, A l g}, k_{N O, A l g}$ and $\left.k_{P O 4, A l g}\right)$ obtained using the 24-L batch data.

542 Our results suggest that, in the absence of dissolved nitrogen species, microalgal growth can be

543 sustained by accessing intracellularly stored nitrogen. A similar case holds for dissolved

544 phosphate, indicating growth utilising internally stored phosphorus (Fig. 6). These findings agree

545 well with published observations (Powell et al., 2008; Coppens et al., 2014), and highlights the

546 relevance of using the Droop model in ASM-A, which uncouples nutrient uptake and storage from

547 microalgal growth.

548 Subsequently, a default parameter set is selected from the different sets obtained in different scales,

549 and the rationale for the selection approach is elucidated in the following. The $I_{A v}$ of 550 photoautotrophic growth and the $K_{I}$ for heterotrophic growth parameters are inferred from the set 
551 estimated using microbatch experiments. The short light path of the microbatches results in an

552 even light distribution. Hence the entire culture is expected to be evenly exposed to the same light

553 intensity. $X_{A l g, N \max }, X_{A l g, N \min }, X_{A l g, P P \max }$ and $X_{A l g, P P \min }$ were set as the overall minimum and maximum

554 values reached and were inferred from sets estimated using 1-L (P quota) and 24-L (N quota) batch

555 experimental data. The heterotrophic growth kinetic parameters and $Y_{A c}$ are inferred from sets

556 estimated using 1-L batch data as we found oxygen limitation under microbatch scale. For model

557 evaluation purposes we selected as default, the above mentioned parameters and the literature

558 values (Table 3, bold values).

$<$ Table 3>

$<$ Table 4>

\section{4.2. Model evaluation}

562 An independent experimental data set (i.e. data obtained in the ascending cycles in the 24-L batch

563 reactor, Fig. 6) is employed as a means for model evaluation (described in section 3.5). In the first

564 evaluation step, the RMSNE values obtained by approximating the experimental data using the

565 simulation model - calibrated with the specific parameter sets obtained through each respective

566 descending cycle (Table 4) - are relatively low and, for algal biomass concentration, ammonium

567 and phosphate concentrations as well as the nitrogen and phosphorus storage, $J \sim 1$ (Table 5). This

568 outcome indicates that culture history does not significantly affect parameters that the

569 aforementioned outputs are sensitive to (hypothesis-I). In most cases, the RMSNE value for the

570 ammonium concentration state-variable is comparably high (Table 5). This is the consequence of

571 normalizing the error using observed values that gives more weight to low magnitude values

572 (Hauduc et al., 2015). As the ammonium bulk concentration decreases below $\sim 0.1$ in most cycles 
573 (e.g. Fig. 5 and 6), the calculated RMSNE value is high (Eq. 1). Hence, $J$ becomes more sensitive

574 in the case of ammonia, giving relatively high values for the evaluation of cycle 7 (Table 5). To

575 further support this hypothesis, the $J$ for cycle 7 is re-calculated using the mean absolute error

576 (MAE), which gives higher penalty to large errors. As expected, the $J$, based on MAE, indicates

577 high accuracy in the validation step $(J=1.65)$. The experimental values of microalgal biomass

578 concentration, bulk ammonium and phosphate concentration and phosphorus storage are in the

579 proximity of the best fit (lowest RMSNE) of the Monte Carlo simulation results (Fig. 6a, 6b, 6d

580 and 6f).

581

$<$ Table 5 $>$

582 This outcome therefore suggests that ASM-A calibrated using the selected mean default parameter 583 set - with the associated uncertainties (Table 4) - can be used to predict algal cultivation in PBRs, 584 in which Chlorella and Scenedesmus are the dominating species (hypothesis-II). This, however, is 585 not the case for predicting the nitrate concentration and, to a lesser extent, the internal nitrogen 586 storage, indicated by experimental data located outside the confidence interval.

588 Nitrogen storage can be predicted in the ascending cycles using the parameters estimated from the 589 parallel descending cycles, i.e. J 1 (Table 5). In the second evaluation step, however, the 590 discrepancy between the predicted and measured nitrogen storage cannot be explained through 591 parameter variability (i.e. most data falls outside the predictive confidence interval, hypothesis-III, 592 Fig 3e). Consequently, substrate availability is assumed to significantly affect the predicted 593 nitrogen storage, thereby indicating the need for case-specific calibration of the nitrogen storage 594 process (hypothesis-II). Finally, the bulk nitrate concentration prediction fails for both evaluation 
595 steps ( $\mathrm{J}>>1$ Table 5, experimental data falls outside the predictive confidence interval, Fig. 6c).

596 This outcome suggests that culture history can significantly impact parameter values associated 597 with bulk nitrate prediction (hypothesis-I).

598 According to the GSA results (Fig. 7; Fig. S11, SI), the most sensitive model parameter, affecting 599 the soluble nitrate concentration is the uptake rate of nitrate $k_{N O, A l g}$, which also affects nitrogen 600 storage (Fig. 7a and 7b). Therefore the identifiability of $k_{N O, A l g}$ is subsequently assessed using the 601 LHSS method (Table S10-S13, SI; Step 5, Fig. 2). We find that based on the histograms obtained 602 (Table S10-S13, SI), the distribution of parameter values estimated is relatively narrow, and 603 standard deviations calculated for each cycle are relatively low $(<40 \%)$, thus suggesting that $k_{N O, A l g}$ 604 is identifiable (Step 5, Fig. 2). Based on the correlation matrix (Table S10-S13, SI), $k_{N O, A l g}$ is highly 605 correlated with the affinity for nitrate. Thus, we assessed the impact of parameter variability on 606 model outputs - analogously to the procedure described in section 4.1.3 (Step 5, Fig. 2). $k_{N O \text {,Alg }}$ 607 was altered to its maximum and minimum value given by the standard deviation separately using 608 the $k_{N O, A l g}$ estimated in each cycle (1-4) (Table 4). Comparably low variation in the outputs $(J \sim 1)$ 609 is obtained (illustrated with an example drawn from cycle 1, Fig. S12, SI), thereby indicating $k_{N O, A l g}$ 610 as identifiable (Step 5, Fig. 2). Since $k_{N O, A l g}$ is identifiable, the case specific calibration of $k_{N O, A l g}$ 611 is recommended. To this end, $k_{N O, A l g}$ was estimated for each cycle, leaving the rest of the parameter 612 kept at the mean values, and results show hysteresis in the parameter value (Fig. 7c). This outcome 613 can serve as a possible explanation to the observations related to the impacts of culture history and 614 substrate availability on nitrate and nitrogen storage predictions.

615 According to Fig. 8 and Fig. S13- S15, using the case-specific calibration of $k_{N O, A l g}$, the increased 616 model accuracy in terms of bulk nitrate does not necessarily translate into improved prediction of 617 the nitrogen storage, possibly as consequence of the scattered data obtained in the 24-L batches 
618 (Fig. 8a and 8c).Therefore, future research should further assess the dynamics of internal nitrogen

619 storage in green microalgal cells that could lead to the re-identification or possible extension of 620 the Droop model.

621

$<$ Figure 7 >

622

$<$ Figure 8 $>$ 


\section{5. Conclusions}

624 This study presents the identification and evaluation of a biokinetic model for photoautotrophic

625 and heterotrophic microalgal growth, developed in the activated sludge modelling framework

626 (ASM-A), thereby facilitating coupled implementations with the already existing simulation

627 model platforms. We conclude that:

628 - Through the specific experimental design and data treatment, the model parameters could be

629 estimated and were identifiable. Furthermore, the experimental design permitted the

630 quantification of model parameter variability caused by culture history and substrate

$631 \quad$ availability.

632 - The average parameter estimates can be used to predict microalgal biomass growth, effluent

633 ammonium and phosphate concentrations and phosphorus storage. This is not the case for the

634 nitrogen storage and soluble nitrate concentration, which depends on the culture history and

635 substrate availability.

636 - The most sensitive parameter affecting the prediction of the soluble nitrate concentration and

637 nitrogen storage is the maximum uptake rate of nitrate. The case specific re-estimation of

$638 k_{N O \text {,Alg }}$ can potentially explain the observations related to the impacts of culture history and

639 substrate availability on nitrate and nitrogen storage predictions. 
641 Dorottya Sarolta Wágner and Borja Valverde-Pérez have contributed equally to the content of

642 this paper. Funding for the study was provided by the European Commission, (E4WATER

643 Project, FP7-NMP-2011.3.4-1 grant agreement 280756). Borja Valverde-Pérez thanks the

644 Integrated Water Technology (InWaTech) project (http://www.inwatech.org) for the financial

645 support. Authors wish to thank Xavier Flores-Alsina and Gürkan Sin (PROCESS-CAPEC,

646 Technical University of Denmark) for their valuable discussions on model identification and

647 calibration and Lydia Garcia (The Natural History Museum of Denmark) for providing help with

648 conducting the PCR analysis and identification of the algal species.

\section{REFERENCES}

650
Adesanya,V. O., Davey, M. P., Scott, S. A., Smith, A. G., 2014. Kinetic modelling of growth and storage molecule production in microalgae under mixotrophic and autotrophic conditions. Bioresource Technology, 157, 293-304.

Alcántara, C., García-Encina, P.A., Muñoz, R., 2013. Evaluation of mass and energy balances in the integrated microalgae growth-anaerobic digestion process. Chemical Engineering Journal, 221, 238-246.

Ambrose, R. B., 2006. Wasp7 benthic algae-model theory and users guide. USEPA, Office of research and development. Athens, Georgia.

APHA. American Public Health Association, 1995. Standard Methods for the Examination of Water and Wastewater. Washington DC.

Arnaldos, M., Amerlinck, Y., Rehman, U., Maere, T., Van Hoey, S., Naessens, W., Nopens, I., 2015. From the affinity constant to the half-staruation index: understanding the conventional modeling concepts in novel wastewater treatment processes. Water Research,70, 458-470.

Béchet, Q., Shilton, A., Guieysse, B., 2013. Modeling the effects of light and temperature on algae growth: State of the art and critical assessment for productivity prediction during outdoor cultivation. Biotechnology Advances, 31, 1648-1663. 
Benavides, M., Telen, D., Lauwers, J., Logist, F., Van Impe, J., Wouwer, A.V., 2015. Parameter identification of the Droop model using optimal experimental design. IFAC-PapersOnLine, 48(1), 589-591.

Benson, B.C., Gutierrez-Wing, M.T., Rusch, K.A., 2007. The development of a mechanistic model to investigate the impacts of the light dynamics on algal productivity in a Hydraulically Integrated Serial Turbidostat Algal Reactor (HISTAR). Aquacultural Engineering, 36, 198-211.

Bernard, O., 2011. Hurdles and challenges for modelling and control of microalgae for $\mathrm{CO}_{2}$ mitigation and biofuel production. Journal of Process Control, 21, 1378-1389.

Bixio, D., Thoeye, C., De Koning, D., Savic, D., Wintgens, T., Melin, T., 2006. Wastewater reuse in Europe. Desalination, 187, 89-101.

Boelee, N.C., Temmink, H., Janssen, M., Buisman, C.J.N., Wijffles, R.H., 2011. Nitrogen removal and phosphorus removal from municipal wastewater effluent using microalgal biofilms. Water Research, 45, 5925-5933.

Bouterfas, R., Belkoura, M., Dauta, A., 2002. Light and temperature effects on the growth rate of three freshwater algae isolated from a eutrophic lake. Hydrobiologia, 489, 207-217.

Brennan, L., Owende, P., 2010. Biofuels from microalgae- A review of technologies for production, processing, and extractions of biofuels and co-products. Renewable and Sustainable Energy Reviews, 14, 557-577.

Broekhuizen, N., Park, J. B. K., McBride, G. B., Craggs, R. J., 2012. Modification, calibration and verification of the IWA River Water Quality Model to simulate a pilot-scale high rate algal pond. Water Research, 46, 2911-2926.

Cai, T., Park, S. Y., Li, Y., 2013. Nutrient recovery from wastewater streams by microalgae: status and prospects. Renewable and Sustainable Energy Reviews, 19, 360-369.

Chandran, K., Smets, B.F., 2005. Optimizing experimental design to estimate ammonia and nitrite oxidation biokinetic parameters from batch respirograms. Water Research, 39, 49694978.

Checchi, N., Marsili-Libelli, S., 2005. Reliability of parameter estimation in respirometric models. Water Research, 39, 3686-3696.

Chen, G., Zhao, L., Qi, Y., 2015. Enhancing the productivity of microalgae cultivated in wastewater toward biofuel production: A critical review. Applied Energy, 137, 282-291.

Clarens, A.F., Ressurreccion, E.P., White, M.A., Colosi, L.M., 2010. Environmental life cycle comparison of algae to other bioenergy feedstocks. Environmental Science and Technology, 44, 1813-1819. 
Coppens, J., Decostere, B., Van Hulle, S., Nopens, I., Vlaeminck, S. E., De Gelder, L., Boon, N., 2014. Kinetic exploration of nitrate-accumulating microalgae for nutrient recovery. Applied Microbiology and Biotechnology, 98 (19), 8377-8387.

Corominas, Ll., Rieger, L., Takács, I., Ekama, G., Hauduc, H., Vanrolleghem, P.A., Oehmen, A., Gernaey, K.V., van Loosdrecht, M.C.M., Comeau, Y., 2011. New framework for standardized notation in wastewater treatment modelling. Water Science and Technology, 61(4), 841-857.

Decostere, B., Janssens, N., Alvarado, A., Maere, T., Goethals, P., Van Hulle, S.W.H., Nopens, I., 2013. A combined respirometer-titrimeter for the determination of microalgae kinetics: experimental data collection and modelling. Chemical Engineering Journal, 222, 85-93.

Decostere, B., Craene, J.D., Van Hoey, S., Vervaeren, H., Nopens, I., Van Hulle, S.W.H., 2016. Validation of a microalgal growth model accounting with inorganic carbon and nutrient kinetics for wastewater treatment. Chemical Engineering Journal, 285, 189-197.

Desmidt, E., Ghyselbrecth, K., Zhang, Y., Pinoy, L., Van der Bruggen, B., Verstraete, W., Rabaey, K., Meesschaert, B., 2015. Global phosphorus scarcity and full-scale P-recovery techniques: A review. Critical Reviews in Environmental Science and Technology, 45, 336384.

Droop, M.R., 1973. Some thoughts on nutrient limitation in algae. Journal of Phycology, 9 (3), 264-272.

Fachet, M., Flassig, R. J., Rihko-Struckmann, L., Sundmacher, K., 2014. A dynamic growth model of Dunaliella salina: Parameter identification and profile likelihood analysis. Bioresource Technology, 173, 21-31.

Fang, L.L., Valverde-Pérez, B., Damgaard, A., Plósz, B.Gy., Rygaard, M., 2016. Life cycle assessment as development and decision support tool for wastewater resource recovery technology. Water Research, 88, 538-549.

Flores-Alsina, X., Gernaey, K.V., Jeppsson, U., 2012. Benchmarking biological nutrient removal in wastewater treatment plants: influence of mathematical model assumptions. Water Science and Technology, 65 (8), 1496-1505.

Flores-Alsina, X., Mbamba, C.K., Solon, K., Vrecko, D., Tait, S., Batstone, D.J., Jeppsson, U., Gernaey, K.V., 2015. A Plant-Wide Aqueous Phase Chemistry Module Describing pH Variations and Ion Speciation/Pairing in Wastewater Treatment Process Models. Water Research, 85, 255-265.

Frutiger, J., Marcarie, C., Abildskov, J., Sin, G., 2016. A Comprehensive Methodology for Development, Parameter Estimation, and Uncertainty Analysis of Group Contribution Based Property Models-An Application to the Heat of Combustion. Journal of Chemical \& Engineering Data,61, 602-613. 
Grady, C.P.L., Smets, B.F., Barbeau, D.S., 1996. Variability in kinetic parameter estimates: a review of possible causes and a proposed terminology. Water Research, 30(3), 742-748.

Grima, E. M., Camacho, F. G., Perez, J. A. S., Sevilla, J. M. F., Fernandez, F. G. A., Gomez, A. C., 1994. A mathematical model for microalgal growth in light-limited chemostat culture. Journal of Chemical Technology and Biotechnology, 61, 167-173.

Guest, J.S., van Loosdrecht, M.C.M., Skerlos, S.J., Love, G.N., 2013. Lumped pathway metabolic model of organic carbon accumulation and mobilization by the alga Chlamydomonas reinhardtii. Environmental Science and Technology, 47, 3258-3267.

Guieysse, B., Béchet. Q., Shilton, A., 2013. Variability and uncertainty in water demand and water footprint assessments of fresh algae cultivation based on case studies from five climatic regions. Bioresource Technology, 128, 317-323.

Guillard, R.R.L., Lorenzen, C.J., 1972. Yellow-Green algae with chlorophyllide. Journal of Phycology, 8 (1), 10-14.

Hauduc, H., Rieger, L., Takács, I., Héduit, A., Vanrolleghem, P.A., Gillot, S., 2010. A systematic approach for model verification: application to seven published activated sludge models. Water Science and Technology, 61(4), 825-839.

Hauduc, H., Neumann, M.B. Muschalla, D., Gamerith, V., Gillot, S., Vanrolleghem, P.A., 2015. Efficiency criteria for environmental model quality assessment: a review and its application to wastewater treatment. Environmental Modelling and Software, 68, 196-204.

Helton, J.C., Davis, F.J., 2003. Latin hypercube sampling and the propagation of uncertainty in analyses of complex systems. Reliability Engineering and System Safety, 81, 23-69.

Henze, M., Gujer, W., Mino, T., Matsuo, T., van Loosdrecht, M.C.M., 2000. Activated Sludge Models ASM1, ASM2, ASM2d and ASM3. London: IWA Publishing.

Huesemann, M.H., Van Wagenen, J., Miller, T., Chavis, A., Hobbs, S., Crowe, B., 2013. A screening model to predict microalgae biomass growth in photobioreactors and raceway ponds. Biotechnology and Bioengineering, 110 (6), 1583-1594.

Lundquist, T., Woertz, I., Quinn, N., Benemann, J., 2010. A realistic technology and engineering assessment of algae biofuel production. Energy Biosciences Institute, University of California Berkeley, California, USA.

Markou, G., Vandamme, D., Muylaert, K., 2014. Microalgal and cyanobacterial cultivation: The supply of nutrients. Water Research, 65, 186-202.

Mata, T.M., Martins, A.A., Caetano, N.S., 2010. Microalgae for biodiesel production and other applications: a review. Renewable and Sustainable Energy Reviews, 14, 217-232. 
Mehta, C.M., Khunjar, W.O., Nguyen, W.O., Tait, S., Batstone, D.J., 2015. Technologies to recover nutrients from waste streams: a critical review. Critical Reviews in Environmental Science and Technology, 45(4), 385-427.

Moya, M.J., Sánchez-Guardamino, M.L., Vilavella, A., Barberá, E., 1997. Growth of Haematococcus lacustris: A Contribution to Kinetic Modelling. Journal of Chemical Technology and Biotechnology, 68, 303-309.

Morales-Sánchez, D., Tinoco-Valencia, R., Kyndt, J., Martinez, A., 2013. Heterotrophic growth of Neochloris oleoabundans using glucose as a carbon source. Biotechnology for Biofuels, $6,100,1-12$.

Mulbry, W., Westhead, E. K., Pizarro, C., Sikora, L., 2005. Recycling of manure nutrients: use of algal biomass from dairy manure treatment as a slow release fertilizer. Bioresource Technology, 96, 451-458.

Muñoz, R., Guieysse, B., 2006. Algal-bacterial processes for the treatment of hazardous contaminants: A review. Water Research, 40, 2799-2815.

Muñoz-Tamayo, R., Martinton, P., Bougaran, G., Mairet, F., Bernard, O., 2014. Getting the most out of it: optimal experiments for parameter estimation of microalgae growth models. Journal of Process Control, 24, 991-1001.

Nelder, J.A., Mead, R., 1965. A simplex-method for function minimization. The Computer Journal, 7(4), 308-313.

Nopens, I., Benedetti, L., Jeppsson, U., Pons, M.N., Alex, J., Copp, J.B., Gernaey, K.V., Rosen, C., Steyer, J.P., Vanrolleghem, P.A., 2010. Benchmark simulation model No 2: finalisation of plant layout and default control strategy. Water Science and Technology, 62(9), 19671974.

Ogawa, T., Aiba, S., 1981. Bioenergetic analysis of mixotrophic growth in Chlorella vulgaris and Scenedesmus acutus. Biotechnology and Bioengineering, 23, 1121-1132.

Olivieri, G., Salatino, P., Marzocchella, A., 2014. Advances in photobioreactors for intensive microalgal production: configurations, operating strategies and applications. Journal of Chemical Technology and Biotechnology, 84, 178-195.

Park, J. B. K., Craggs, R. J., 2011. Nutrient removal in wastewater treatment high rate algal ponds with carbon dioxide addition. Water Science and Technology, 63, 1758-1764.

Perez-Garcia, O., Escalante, F. M. E., de-Bashan, L. E., Bashan, Y., 2011. Heterotrophic cultures of microalgae: Metabolism and potential products. Water Research, 45, 11-36.

Pittman, J. K., Dean, A. P., Osundeko, O., 2011. The potential of sustainable algal biofuel production using wastewater resources. Bioresource Technology, 102, 17-25. 
804

805

806

807

808

809

810

811

812

813

814

815

816

817

818

819

820

821

822

823

824

825

826

827

828

829

830

831

832

833

834

835

836

837

Powell, N., Shilton, A.N., Pratt, S., Chisti, Y., 2008. Factors influencing luxury uptake of phosphorus by microalgae in waste stabilization ponds. Environmental Science and Technology, 42, 5958-5962.

Quinn, J., de Winter, L., Bradley, T., 2011. Microalgae bulk growth model with application to industrial scale systems. Bioresource Technology, 102, 5083-5092.

Ras, M., Steyer, J.-P., Bernard, O., 2013. Temperature effect on microalgae: a crucial factor for outdoor production. Reviews in Environmental Science and Biotechnology, 12, 153-164.

Richmond, A., 2004. Handbook of Microalgal Culture Biotechnology and Applied Phycology. Blackwell Publishing: Oxford.

Romero-García, J.M., Acién-Fernández, F.G., Fernández- Sevilla, J.M., 2012. Development of a process for the production of L-amino-acids concentrates from microalgae by enzymatic hydrolysis. Bioresource Technology, 112, 164-170.

Saltelli, A., Ratto, M., Andres, T., Campolongo, F., 2008. Global Sensitivity Analysis: the Primer. John Wiley \& Sons, West Sussex, England.

Samorí, G., Samorí, C., Guerrini, F., Pistocchi, R., 2013. Growth and nitrogen removal capacity of Desmodesmus communis and of natural microalgae consortium in a batch culture system in view of urban wastewater treatment: Part 1.Water Research, 47, 791-801.

Shilton, A. N., Powell, N., Guieysse, B., 2012. Plant based phosphorus recovery from wastewater via algae and macrophytes. Current Opinion in Biotechnology, 23, 884-889.

Sin, G., De Pauw, D.J.W., Weijers, S., Vanrolleghem, P.A., 2007. An efficient approach to automate the manual trial and error calibration of activated sludge models. Biotechnology and Bioengineering, 100(3), 516-528.

Sin, G., Gernaey, K. V., Neumann, M.B., van Loosdrecht, M.C.M., Gujer, W., 2009. Uncertainty analysis in WWTP model applications: a critical discussion using an example from design. Water Research, 43, 2894-2906.

Sin, G., Meyer, A.S., Gernaey, K.V., 2010. Assessing reliability of cellulose hydrolysis models to support biofuel process design-Identifiability and uncertainty analysis. Computers and Chemical Engineering, 34, 1385-1392.

Sin, G., Gernaey, K. V., Neumann, M.B., van Loosdrecht, M.C.M., Gujer, W., 2011. Global sensitivity analysis in wastewater treatment plant model applications: Prioritizing sources of uncertainty. Water Research, 45, 639-651.

Skjelbred, B., Edvardsen, B., Andersen, T., 2012. A high-throughput method for measuring growth and loss rates in microalgal cultures. Journal of Applied Phycology, 24(6), 15891599. 
Snip, L.J.P., Boiocchi, R., Flores-Alsina, X., Jeppsson, U., Gernaey, K.V., 2014. Challenges encountered when expanding activated sludge models: a case study based on $\mathrm{N}_{2} \mathrm{O}$ production. Water Science and Technology, 70(7), 1251-1260.

Tchobanoglous, G.; Burton, F.L; Stensel, H.D., 2004. Wastewater engineering treatment and reuse, $4^{\text {th }}$ Edition. McGraw-Hill: New York.

Turon, V., Baroukh, C., Trably, E., Latrille, E., Fouilland, E., Steyer, J.-P., 2015. Use of fermentative metabolites for heterotrophic microalgae growth: Yields and kinetics. Bioresource Technology, 175, 342-349.

Valverde-Pérez, B., Ramin, E., Smets, B.F., Plósz, B.Gy., 2015. EBP2R - An innovative enhanced biological nutrient recovery activated sludge system to produce growth medium for green microalgae cultivation. Water Research, 68, 821-830.

Valverde-Pérez, B., Fuentes-Martínez, J.M., Flores-Alsina, X., Gernaey, K.V., Huusom, J.K., Plósz, B. Gy., 2016. Control structure design for resource recovery using the enhanced biological phosphorus removal and recovery (EBP2R) activated sludge process. Chemical Engineering Journal, 296, 447-457.

Van Daele T., Van Hoey S., Gernaey K.V., Krühne U., Nopens I., 2015. A numerical procedure for model identifiability analysis applied to enzyme kinetics. Computer Aided Process Engineering, 37, 575-580.

Van Den Hende, S., Carré, E., Cocaud, E., Beelen, V., Boon, N., Vervaeren, H., 2014. Treatment of industrial wastewaters by microalgal bacterial flocs in sequencing batch reactors. Bioresource Technology, 161, 245-254.

Van Loosdrecht, M.C.M., and Henze, M., 1999. Maintenance, endogeneous respiration, lysis, decay and predation. Water Science and Technology, 39(1), 107-117.

Van Wagenen, J., Holdt, S. L., De Francisci, D., Valverde-Pérez, B., Plósz, B. Gy., Angelidaki, I., 2014. Microplate-based method for high-throughput screening of microalgae growth potential. Bioresource Technology, 169, 566-572.

Van Wagenen, J., De Francisci, D., Angelidaki, I., 2015a. Comparison of mixotrophic to cyclic autotrophic/heterotrophic growth strategies to optimize productivity of Chlorella sorokiniana. Journal of Applied Phycology, 27(5), 1775-1782.

Van Wagenen, J., Pape, M.L., Angelidaki, I., 2015b. Characterization of nutrient removal and microalgal biomass production on an industrial waste-stream by application of the deceleration-stat technique. Water Research, 75, 301-311.

Verstraete, W., Van de Caveye, P., Diamantis, V., 2009. Maximum use of resources present in domestic "used water". Bioresource Technology, 100, 5537-5545. 
872 Verstraete, W., Vlaeminck, S. E., 2011. ZeroWasteWater: short-cycling of wastewater resources 873 for sustainable cities of the future. International Journal of Sustainable Development and $874 \quad$ World Ecology, 18(3), 253-264.

875 Wágner, D.S., Valverde-Pérez, B., Sæbø, M., Van Wagenen, J., Angelidaki, I., Smets, B.F., $876 \quad$ Plósz, B. Gy., 2014. The effect of light on mixed green micro-algae growth - experimental 877 assessment and modelling. IWA World Water Congress and Exhibition, 21-26 September, $878 \quad$ 2014, Lisbon, Portugal.

879 Wang, L., Min, M., Li, Y., Chen, P., Chen, Y., Liu, Y., Wang, Y., Ruan, R., 2010. Cultivation of 880 green algae Chlorella sp. in different wastewaters from municipal wastewater treatment plant. Applied Biochemistry and Biotechnology, 162, 1174-1186.

882 Wijffels, R. H., Barbosa, M. J., 2010. An outlook on microalgal biofuels. Science, 329, 796-799.

883 Wilhelm, C., Jakob, T., 2011. From photons to biomass and biofuels: evaluation of different strategies for the improvement of algal biotechnology based on comparative energy balances. Applied Microbiology and Biotechnology, 92, 909-919.

886 Wolf, G., Picioreanu, C., van Loosdrecht, M.C.M., 2007. Kinetic modeling of phototrophic 887 biofilms: the PHOBIA model. Biotechnology and Bioengineering, 97 (5), 1064-1079. 